\title{
Development of Cognitive Abilities through the Abacus in Primary Education Students: A Randomized Controlled Clinical Trial
}

\author{
Samuel P. León ${ }^{1}$ (D), María del Carmen Carcelén Fraile ${ }^{1}$ and Inmaculada García-Martínez ${ }^{2, *(D)}$ \\ 1 Department of Pedagogy, University of Jaén, 23071 Jaén, Spain; sparra@ujaen.es (S.P.L.); \\ mccf0004@red.ujaen.es (M.d.C.C.F.) \\ 2 Department of Education, University of Almería, 04120 Almería, Spain \\ * Correspondence: imartin@ual.es; Tel.: +34-950015258
}

Citation: León, S.P.; Carcelén Fraile, M.d.C.; García-Martínez, I. Development of Cognitive Abilities through the Abacus in Primary Education Students: A Randomized Controlled Clinical Trial. Educ. Sci. 2021, 11, 83. https:// doi.org/10.3390/educsci11020083

Received: 28 January 2021

Accepted: 17 February 2021

Published: 21 February 2021

Publisher's Note: MDPI stays neutral with regard to jurisdictional claims in published maps and institutional affiliations.

Copyright: (c) 2021 by the authors. Licensee MDPI, Basel, Switzerland. This article is an open access article distributed under the terms and conditions of the Creative Commons Attribution (CC BY) license (https:// creativecommons.org/licenses/by/ $4.0 /)$.

\begin{abstract}
Background: An abacus is an instrument used to perform different arithmetic operations. The objective was to analyze the benefits of mathematical calculations made with an abacus to improve the concentration, attention, memory, perceptive attitudes, and creativity cognitive abilities of primary school students. (2) Methods: A total of 65 children, aged 7-11 years (8.49 \pm 1.65$)$ participated in this randomized controlled clinical trial. The children were randomly distributed into a control group $(n=34)$ and experimental group $(n=31)$. The questionnaires used were the D2 test to measure attention and concentration, the Difference Perception Test (FACE-R) test for the perception of differences, the test of immediate auditory memory (AIM), and the test to evaluate creative intelligence (CREA). (3) Results: No significant differences were found between both groups before the intervention. Significant improvements were observed in the cognitive parameters of concentration, memory, perceptive attitudes, and creativity after the intervention, using the abacus, with respect to the control group. (4) Conclusions: It is demonstrated that a calculation program based on the use of the abacus for 8 weeks has beneficial effects on the cognitive capacities of concentration, immediate auditory memory, perceptive attitudes, and creativity. In addition, the benefits of using the abacus to improve cognitive attitudes are reported.
\end{abstract}

Keywords: abacus; intervention; calculus; cognitive ability; children

\section{Introduction}

Calculation training of mental abilities with an abacus affects the cognitive processes developed to perform arithmetic operations [1]. The literature has found that abacus training has significant implications for the improvement of children's academic performance [2]. In fact, many studies have attempted to understand how the brain works when someone uses an abacus to acquire arithmetic skills [3,4].

In this regard, it has been shown that mental skills training enhances brain plasticity [5] in terms of functional brain activation, connectivity, and anatomy [6]. Several papers have identified that learning new skills can lead to structural and functional brain reorganization $[7,8]$. Furthermore, in recent studies, it has been shown that training through abacus-based mental calculations (AMC) promotes arithmetic literacy and, thus, the improvement of cognitive abilities $[9,10]$.

The technological revolution has entered schools and the use of innovative strategies and materials to assist children in learning is becoming more widespread [1]. AMC training has received special attention for the improvement of both math and cognitive skills [11-13].

Abacus arithmetic is one of the most common methods of early childhood mathematics education in Asia [3,14]. The abacus is an ancient type of calculator [15] that has been used to develop various complex arithmetic operations, such as addition, subtraction, multiplication, division, square root, and cubic root, and is considered the first machine 
capable of performing calculations [12]. The numbers are represented through an arrangement of accounts in columns, each of which represents a positional value that increases from right to left [16] (see Figure 1).

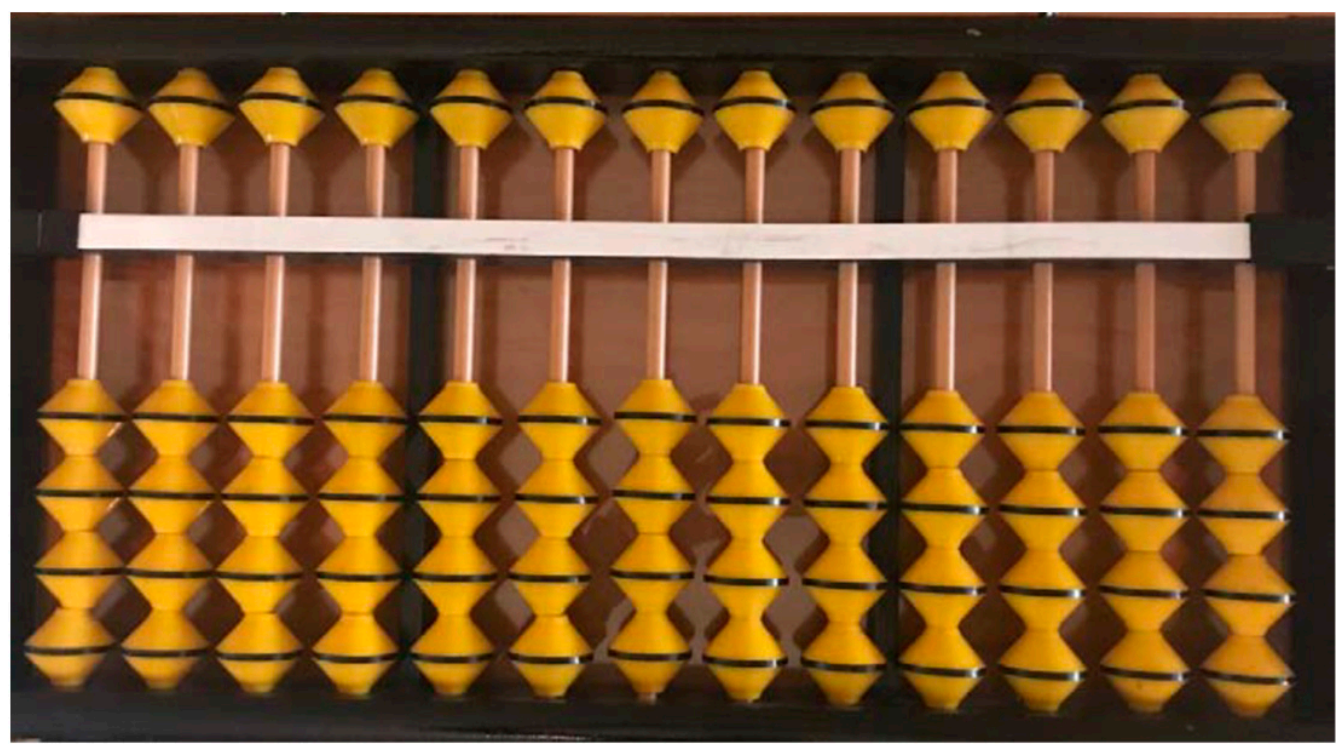

Figure 1. Soroban abacus.

People trained to work with the abacus with mental calculations can perform all the above-mentioned arithmetic operations, in addition to the physical instrument, with mental calculations, carried out with great speed [17]. This skill can be acquired by carrying out certain steps with good long-term training $[4,5,10]$. Mental arithmetic of the abacus involves the skillful acquisition of different signs that represent mathematical algorithms to properly manipulate an imaginary abacus [18].

Abacus training requires a certain number of phases to become an expert [1]. In this regard, people who use the abacus initially learn to perform abacus counting on the instrument using both hands. Therefore, when they progress in math, they learn to imagine in order to perform methodical counting with their mind. As their calculation skills improve, the next step is to perform the same operations with an imaginary abacus, with no real movements with their fingers. Generally, people who are experts in the use of the abacus have a great capacity to calculate 10-digit numbers with their minds, even with more precision and speed $[19,20]$.

Psychological [18] and neuroscience [21] studies have verified that some patterns of brain activation of people who have studied the method in-depth are different from those people who do not practice this method [3], and most calculation skills improve significantly after abacus training compared to reference control subjects [20]. Although the effects of AMC training are significant, the latent neural mechanism that produces increased neural plasticity and synaptic improvement remains difficult to explain $[5,9]$.

Considering that the left hemisphere focuses on words, hearing associations, logic, among others, and the right one on emotions, intuition, but above all, on images, it is of great importance to understand and know how the numerical calculation is carried out [22]. Normally, people process and receive numerical inputs in the left hemisphere (language). However, people who work with the abacus to perform calculations also activate the right one [3]. In the first instance, the numerical information is sent through the nerve fibers (corpus callosum) reaching the right hemisphere, which is where the translation into natural language (spatial arrangement, images) takes place [23].

At this point, the students may manipulate an imaginary abacus in order to solve the different arithmetic operations [24]. With accuracy and speed, those who train with the abacus obtain the solution that will be translated back into numerical language immediately 
afterward. To carry out this whole process, the information travels back through the corpus callosum until it reaches the left hemisphere [25]. Just by doing this, people who perform mathematical calculations with the abacus work on the development of the whole brain [26].

In addition, authors such as Tanaka et al. [27] examined the significant differences found between both hemispheres for performing different tasks. According to these authors, there is a tendency to have one hemisphere be dominant over the other regarding information processing. However, this dominance concept should not be dichotomized since the creative process demands cooperation between both hemispheres.

Another important point about the use of the abacus is its relationship with the promotion of manipulative resources, which are essential for improving children's cognitive skills in mathematics [28].

Children exposed to AMC training may solve complex calculation problems with unusually fast speed and high accuracy [29]. People who are trained by this method become highly capable of performing mathematical calculations more quickly after longterm training $[20,30]$.

In the beginning, individuals learn to calculate with a real abacus, and they use both hands at the same time. Later, once they become familiar with the operation, they are encouraged to mentally carry out the calculation process with the abacus with real movements of the fingers in the air [1]. Finally, they are able to calculate through an imaginary abacus without moving their fingers, as if they were manipulating a "mental abacus" [31,32]. Taking into account the evidence in the literature about how the abacus changes the way that we draw on each hemisphere to perform mental calculations and its possible impact on other mental abilities, the findings of which are not consistent, this study aims to contribute to the area of study on the benefits of abacus training from a more educational perspective. In particular, the aim is to provide further evidence to the field of mathematics instruction and cognitive and socioconstructivist learning theories. The use of the abacus for learning arithmetic calculations, in addition to increasing students' involvement in the learning process, promotes their integral development, critical thinking, and autonomy. Specifically, the aim of our study was to analyze the benefits of using the abacus in mathematical calculations on the concentration, attention, memory, perceptive attitudes, and creativity cognitive abilities in primary school students. Furthermore, the research questions that guided this study were: (i) Is there a relationship between AMC training and the development of cognitive skills in primary school students?; (ii) Does the abacus-based intervention achieve significantly better results than the control group who underwent a traditional intervention?

According to our initial hypothesis, we expected that AMC training would produce an improvement in cognitive abilities among children between 7 and 11 years old with respect to the control group, which carried out training in mental calculations following a traditional approach.

\section{Materials and Methods}

A randomized controlled clinical trial was conducted, which included an experimental design analyzing the effects of 8 weeks of soroban abacus exercise intervention on concentration, attention, memory, perceptive attitudes, and creativity in children aged 7-11 years. This study analyzed the effectiveness of abacus training as a tool in children attending training classes for the improvement of intellectual capacities in the field of psychological education.

\subsection{Participants}

A total of 65 children $(8.49 \pm 1.65)$ participated in the study distributed into two groups, a control group $(n=34)$ and an experimental group $(n=31)$. Of all the participants, 38 were boys and 27 were girls (58.46\% vs. $41.54 \%$ ). Most of them belonged to the 
first year of Primary Education (21.53\%) and only 10.77\% belonged to the sixth year of Primary Education.

The target population of our study was children who (i) were aged between 7 and 11; (ii) were not enrolled in any kind of reinforcement classes or mental exercise training, with the aim of achieving benefits in school performance, apart from the primary education classes received in their school/institute; (iii) were sufficiently capable of carrying out the different questionnaires for the assessment of cognitive skills and the elaboration of the exercises proposed by the teacher that were included in our study. All children were excluded if (i) they had some type of neurological pathology that prevented them from carrying out the study properly; (ii) they were familiar with the technique and had done exercises with the abacus in the last year; (iii) they were absent from more than three sessions, even if the cause was justified by their legal guardians; (iv) they were already participating in another type of cognitive training given outside their school hours in their corresponding school.

\subsection{Instruments}

The following questionnaires were used in this study:

- The D2 test, in its Spanish version [33], assesses selective attention and concentration in the school context. The participant's task is to check carefully, starting from left to right, what is written on each line and must mark all the letters that have two small lines (two bottom, two top or one bottom and one top) with a " $\mathrm{d}$ ". These elements are considered relevant. The other combinations (the " $\mathrm{d}$ " and " $\mathrm{p}$ ", with and without stripes) are known as irrelevant, and they should not be marked. The participant has $20 \mathrm{~s}$ for each line. This test has shown excellent reliability, with ranges between 0.90 and 0.97 for both the Cronbach $\alpha$ and test-retest, and has also shown convergent and divergent validity [34].

- The Difference Perception Test (FACE-R) [35] measures the ability to quickly and accurately appreciate differences and similarities in different sequential stimulation patterns. This test evaluates attentional and perceptive skills through 60 graphic items composed of representative pictures of faces with basic strokes. The task that is carried out in this test is based on seeing which of the three faces presents a different feature. The application form can be individual or collective in a rather short time, approximately $3 \mathrm{~min}$. Using this test, we can obtain a measure of Differential Perception (DP) and, additionally, we can calculate the Impulsivity Control Index (ICI) manifested in the impulsivity shown by subjects during the task. This test has shown high reliability (Cronbach' $\alpha=0.91$ ), in addition to convergent and divergent validity in the normative data sample [36].

- The immediate auditory memory test (AIM) [37] evaluates immediate memory aspects related to auditive perception. The test is composed of three parts: logical memory, in which the participant is read two paragraphs and attempts to note them down until the participant is satisfied in order to remember the details that appear in the narration; numerical memory, in which a set of digits is used that the person has to repeat, first in order and then inversely; and associative memory, which is composed of ten pairs of words that are told to the participant during three different moments, which are discovered by the subject with the aim of associating them with those that the examiner successively dictates. The test has shown accepted reliability indexes (Cronbach' $\alpha=0.80$ ) [38].

- The Creative Intelligence Test (CREA) [39] is used to assess creative intelligence by cognitively evaluating creativity individually according to the reproduction of issues indicators within a theoretical context of research and problem-solving. The procedure consisted of showing a photograph to the child and asking him/her to fill in the blanks at the top of the copy with the data that appeared. The task is based on writing down, in a brief form, as many pre-questions as possible about what it shows. The CREA test 
has been found to meet the standards of reliability (Cronbach' $\alpha=0.875)$ and validity required of a psychological test [40].

All questionnaires were given to the participants before starting the intervention and after the end of the treatment period.

\subsection{Procedure}

For the recruitment of the participants, we contacted the company Aloha Mental Arithmetic, which is an educational support and tutoring establishment, located in Jaén (Spain). A meeting was held there with the parents or the child's legal guardians of incoming students to inform them about the study and ask them to participate in our training program for the improvement of mental abilities. Out of a total of 73 people who were initially contacted and evaluated after meeting the inclusion criteria of our study, 65 met all the inclusion criteria proposed in our study and were accepted for participation. The ethical standards that guide research with individuals, according to the Declaration of Helsinki, were followed [41].

Once the informed consent of the parents or the child's legal guardians was obtained to participate, children were assigned randomly, using a random number table generated by a computer, dividing the whole sample into a control group (CG) that was not subjected to training with the abacus, but which did exercises of mathematical reinforcement with the conventional method, and an experimental group (EG) that carried out an intervention of 8 weeks with abacus exercises, in a proportion of 1:1. Participants, researchers, and teachers were blinded in the group assignment. The assignment was carried out with closed and stamped, opaque, and consecutively numbered packets in an unlocked place, which were then opened by someone independent from the study.

Regarding the administration of the instruments, all questionnaires were passed to participants before starting the training and after the end of the intervention period.

\subsection{Intervention}

Firstly, children assigned to the control group received academic reinforcement classes in groups for two sessions per week. Each of the sessions lasted $60 \mathrm{~min}$ and consisted of $10 \mathrm{~min}$ for the review of the contents that the children had been given in class in the morning, $30 \mathrm{~min}$ for the completion of exercises from the school textbook of each child, and finally, $20 \mathrm{~min}$ for the performance of mathematical exercises similar to the previous ones, presented in a set of cards prepared by teachers in order to check that the participants had properly understood the contents.

Regarding the participants assigned to the EG, they received two weekly abacus exercise sessions (one hour per session) for 8 weeks. Each session was divided into three phases: a warm-up (5 min), in which a brief review of the correct abacus movements was done. For this purpose, it is important to bear in mind that to raise the abacus pieces it is necessary to do it with the thumb finger and to lower them with the index one. On the other hand, to manipulate the top piece corresponding to the number five, these movements were performed only with the index finger. In addition, the new calculations learned on the previous day were reviewed: the main phase $(45 \mathrm{~min})$, in which the method exercises were performed in steps, and the correction phase $(10 \mathrm{~min})$ to correct the exercises performed in class and resolve doubts from the participants. In addition, during the intervention, the participants' legal guardians were periodically contacted to ensure that they did not perform any type of exercise outside those proposed in the research.

Regarding the main phase of the sessions, in Session 1, the parts of the soroban abacus and the value of the pieces were explained to the children. In Sessions 2 and 3, they were taught how to perform direct addition and subtraction with one digit, that is, the addition and subtraction of pieces indicated without using formulas. In Sessions 4 and 5, they were introduced to the mental calculations of direct addition and subtraction in which the children had to visualize the abacus in their head and move the pieces on their mental abacus. In Sessions 6 and 7, the little friends (terminology that refers to the numbers that 
are missing to reach another number, e.g., the number 1 is missing 4 to reach 5 , so 1 is a little friend of 4) were applied in addition to being used when a calculation could not be performed directly because there were not enough pieces in the row to be added. In Sessions 8 and 9, the same little friends were used, but, in this case, when there are not enough pieces in the row to be subtracted. In Sessions 10 and 11, direct addition and subtraction with two digits were carried out, in which the children had to use two rows of the abacus. In Sessions 12 and 13, the children learned to perform mental calculations of direct addition and subtraction with two digits. Finally, in the last three sessions, the children were taught how to perform direct addition and subtraction with three digits.

\subsection{Data Analysis}

The different statistical analyses were performed with Jamovi software, a free and open statistical software [42]. Mean values, standard deviations, number of cases, and percentage of the total were calculated for each study variable. To see any differences between the groups, a Student $t$-test was used for continuous variables, and the chi-square statistical test for categorical variables. A multiple repeated measures analysis of variance (MRMANOVA) was performed with all study variables to analyze possible differences between the groups (EG vs. CG) over time (Pre vs. Post) for each of the variables evaluated. The dependent variables were the scores achieved in the D2 test and the difference perception test (FACE-R), measured in hits and errors; the immediate auditory memory test (AIM) and the creative intelligence test (CREA) measured as hits. An ANOVA was carried out separately for each of the dependent variables; and finally, a planned post hoc comparison was performed to analyze interaction effects and principles in each variable to analyze the possible interaction between the treatment and measurement time. In all cases, the probability value " $\alpha$ " was set at 0.05 . A partial eta-squared value with a $95 \%$ confidence interval was used to report the effect size of each analysis.

\section{Results}

Three CG participants did not attend the measurement session after the intervention. Table 1 presents the descriptive results at the beginning of the study for the sociodemographic variables and for the cognitive ones.

Table 1. Participants' baseline characteristics.

\begin{tabular}{|c|c|c|c|c|c|}
\hline Characteristics & & Total $(n=65)$ & $\mathrm{EG}(n=34)$ & CG $(n=31)$ & $p$-Value \\
\hline Age & & $8.49 \pm 1.65$ & $8.56 \pm 1.56$ & $8.41 \pm 1.77$ & 0.736 \\
\hline \multirow[b]{2}{*}{ Sex } & Girls & $27(41.54)$ & $14(51.9)$ & $13(48.1)$ & \multirow[b]{2}{*}{0.951} \\
\hline & Boys & $38(58.46)$ & $20(52.6)$ & $18(47.4)$ & \\
\hline \multirow{6}{*}{ Academic course } & $1^{\circ}$ & $14(21.53)$ & $6(42.9)$ & $8(57.1)$ & \multirow{6}{*}{0.911} \\
\hline & $2^{\circ}$ & $8(12.31)$ & $4(50)$ & $4(50)$ & \\
\hline & $3^{\circ}$ & $11(16.92)$ & $7(63.6)$ & $4(36.4)$ & \\
\hline & $4^{\mathrm{o}}$ & $13(20)$ & $7(53.8)$ & $6(46.2)$ & \\
\hline & $5^{\circ}$ & $12(18.46)$ & $7(58.3)$ & $5(41.7)$ & \\
\hline & $6^{\circ}$ & $7(10.77)$ & $3(42.9)$ & $4(57.1)$ & \\
\hline Siblings & & $0.95 \pm 0.78$ & $1.15 \pm 0.86$ & $0.74 \pm 0.63$ & 0.198 \\
\hline \multirow{2}{*}{ Lenses use } & No & $44(67.69)$ & $23(53.3)$ & $21(47.7)$ & \multirow{2}{*}{0.993} \\
\hline & Yes & $21(32.31)$ & $11(52.4)$ & $10(47.6)$ & \\
\hline Concentration & & $62.15 \pm 15.69$ & $62.56 \pm 13.50$ & $61.71 \pm 18.00$ & 0.829 \\
\hline Attention & & $67.58 \pm 12.92$ & $70.29 \pm 9.51$ & $64.61 \pm 15.47$ & 0.077 \\
\hline Difference perception & & $4.55 \pm 1.76$ & $4.53 \pm 1.38$ & $4.58 \pm 2.13$ & 0.908 \\
\hline Impulsivity Control Index & & $4.74 \pm 1.58$ & $5.15 \pm 1.28$ & $4.29 \pm 1.77$ & 0.099 \\
\hline Logical memory & & $26.92 \pm 8.54$ & $26.21 \pm 7.51$ & $27.71 \pm 9.60$ & 0.483 \\
\hline
\end{tabular}


Table 1. Cont

\begin{tabular}{ccccc}
\hline Characteristics & Total $(\boldsymbol{n}=\mathbf{6 5})$ & EG $(\boldsymbol{n}=\mathbf{3 4})$ & CG $(\boldsymbol{n}=\mathbf{3 1})$ & $\boldsymbol{p}$-Value \\
\hline Numerical memory & $9.51 \pm 2.22$ & $8.85 \pm 2.32$ & $10.23 \pm 1.89$ & 0.012 \\
\hline Associative memory & $28.57 \pm 7.25$ & $28.06 \pm 7.15$ & $29.13 \pm 7.43$ & 0.556 \\
\hline $\begin{array}{c}\text { Total score } \\
\text { AIM }\end{array}$ & $74.51 \pm 18.13$ & $71.97 \pm 17.75$ & $77.29 \pm 18.42$ & 0.240 \\
\hline Creativity & $53.69 \pm 21.42$ & $51.29 \pm 20.73$ & $56.32 \pm 22.20$ & 0.349 \\
\hline
\end{tabular}

Notes. Quantitative variables are presented as mean \pm standard deviation. Qualitative variables are presented as frequency (percentage); EG: experimental group; CG: control group; AIM: immediate auditory memory test.

The differences between the groups for each variable were analyzed using a Student $t$-test. As it can be observed, the EG students showed lower pre-scores for the Numerical Memory variable than the CG students. The rest of the variables showed no significant differences, although, for the Attention variable, the difference was marginal (0.077).

In order to analyze whether the intervention in the different groups developed over time for each of the dependent variables measured, a multiple repeated measures analysis of variance (MR-MANOVA) was performed. The results are presented in Table 2.

Table 2. Multiple repeated measures analysis of variance (MR-MANOVA).

\begin{tabular}{ccccccc}
\hline & Sum of Squares & $\mathbf{d f}$ & Mean Square & $\boldsymbol{F}$ & $\boldsymbol{p}$ & $\boldsymbol{\eta}^{\mathbf{2}} \mathbf{p}$ \\
\hline DV & $836,961.14$ & 8 & $104,620.14$ & 606.94 & $<0.001$ & 0.91 \\
DV $*$ Group & 1164.05 & 8 & 145.51 & 0.84 & 0.564 & 0.01 \\
Residual & $86,875.63$ & 504 & 172.37 & & & \\
Time & 620.68 & 1 & 620.68 & 114.86 & $<0.001$ & 0.65 \\
Time $*$ Group & 1121.33 & 1 & 1121.33 & 207.51 & $<0.001$ & 0.77 \\
Residual & 340.44 & 63 & 5.40 & & & \\
DV $*$ Time & 1159.55 & 8 & 144.94 & 36.95 & $<0.001$ & 0.37 \\
DV $*$ Time $*$ Group & 1863.33 & 8 & 232.92 & 59.37 & $<0.001$ & 0.49 \\
Residual & 1977.22 & 504 & 3.92 & & & \\
\hline Group & 411.11 & 1 & 411.11 & 0.35 & 0.557 & 0.01 \\
Residual & $74,441.43$ & 63 & 1181.61 & & & \\
\hline Note. DV D Dependent variable; Time $=$ different time measure (Pre vs. Post); Group = EG vs. CG.
\end{tabular}

Note. DV = Dependent variable; Time = different time measure (Pre vs. Post); Group = EG vs. CG.

As can be seen, there was a main effect of the dependent variable and an experimental main effect of time. More interesting are the double interactions, Time $\times$ Group, and DV $\times$ Time, and even more so, the triple interaction DV $\times$ Time $\times$ Group. No other effects were significant. These results indicate that the measured variables changed differently between the groups after the intervention.

Figure 2 represents the means of the different dependent variables measured in the study for the pre-intervention (Pre) and post-intervention (Post) measurements for each of the groups (CG represented with gray lines and EG represented with black lines). The error bars on each mediation represent the $95 \%$ confidence interval.

In order to further analyze how the different variables changed over time for each treatment group, a 2 Group (EG vs. CG) $\times 2$ Time (Pre vs. Post) was performed for each of the dependent variables. Below, we present the results of each of the analyses; the capitalized letter that accompanies each variable indicates the graph that corresponds with it in Figure 1. Results for each variable are presented in Table 3.

\section{D2: (A) Concentration and (B) Selective Attention}

The analyses showed a double interaction Time $\times$ Group for the concentration variable. Planned post hoc comparisons showed that the double interaction found was due to a significant difference between Pre and Post for the EG group, $\mathrm{t}(63)=-3.65, p_{\text {bonferroni }}=0.003$. No other effect was significant in concentration, nor for the attention variable. 

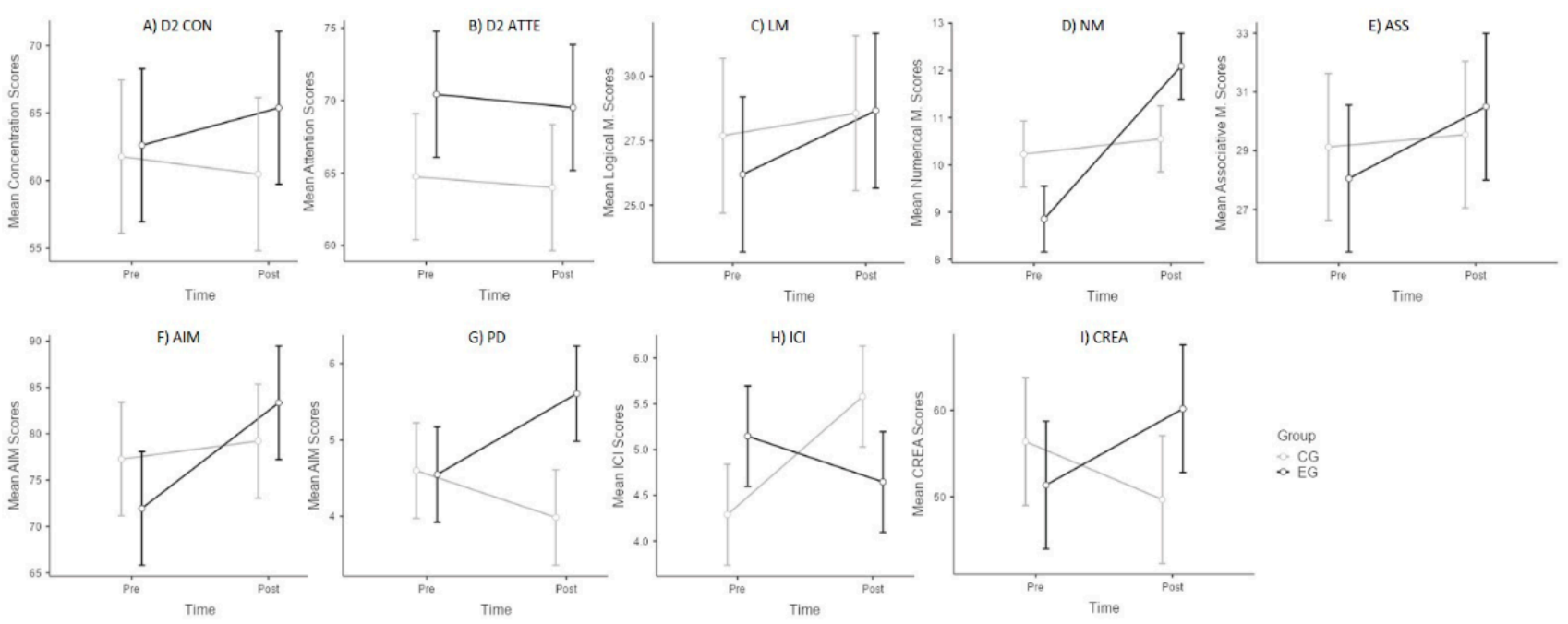

Figure 2. Comparison of dependent variable scores over time for each group. Notes. (A) D2 CON = Concentration Score; (B) D2 ATTE = Attention Score; (C) LM = Logical Memory; (D) NM = Numerical Memory; (E) ASS = Associative Memory; (F) AIM Total Immediate Auditory Memory; (G) PD = Difference Perception; (H) ICI = Impulsivity Control Index; (I) CREA = Creativity.

Table 3. Summary results for the comparisons of each dependent variable.

\begin{tabular}{|c|c|c|c|c|c|c|c|}
\hline DV & VI & SS & df & Mean Square & $\mathbf{F}$ & $p$ & $\eta^{2} p$ \\
\hline \multirow[t]{3}{*}{$\mathrm{D} 2 \mathrm{CON}$} & Time & 17.62 & $(1,63)$ & 17.62 & 1.80 & 0.184 & 0.03 \\
\hline & Time $*$ Group & 133.32 & $(1,63)$ & 133.32 & 13.65 & $<0.001$ & 0.18 \\
\hline & Group & 268.37 & $(1,63)$ & 268.37 & 0.52 & 0.471 & 0.01 \\
\hline \multirow[t]{3}{*}{ D2 Atte } & Time & 22.17 & $(1,63)$ & 22.17 & 1.98 & 0.164 & 0.03 \\
\hline & Time $*$ Group & 0.23 & $(1,63)$ & 0.23 & 0.02 & 0.885 & 0.00 \\
\hline & Group & 1015.69 & $(1,63)$ & 1015.69 & 3.42 & 0.069 & 0.05 \\
\hline \multirow[t]{3}{*}{ LM } & Time & 90.53 & $(1,63)$ & 90.53 & 27.69 & $<0.001$ & 0.31 \\
\hline & Time $*$ Group & 20.75 & $(1,63)$ & 20.75 & 6.35 & 0.014 & 0.09 \\
\hline & Group & 16.07 & $(1,63)$ & 16.07 & 0.11 & 0.739 & 0.00 \\
\hline \multirow[t]{3}{*}{ NM } & Time & 102.63 & $(1,63)$ & 102.63 & 159.86 & $<0.001$ & 0.72 \\
\hline & Time $*$ Group & 68.78 & $(1,63)$ & 68.78 & 107.14 & $<0.001$ & 0.63 \\
\hline & Group & 0.23 & $(1,63)$ & 0.23 & 0.03 & 0.861 & 0.00 \\
\hline \multirow[t]{3}{*}{ ASS } & Time & 66.34 & $(1,63)$ & 66.34 & 97.28 & $<0.001$ & 0.61 \\
\hline & Time $*$ Group & 33.14 & $(1,63)$ & 33.14 & 48.60 & $<0.001$ & 0.44 \\
\hline & Group & 0.11 & $(1,63)$ & 0.11 & 0.00 & 0.973 & 0.00 \\
\hline \multirow[t]{3}{*}{ AIM } & Time & 1438.02 & $(1,63)$ & 1438.02 & 240.34 & $<0.001$ & 0.79 \\
\hline & Time $*$ Group & 723.56 & $(1,63)$ & 723.56 & 120.93 & $<0.001$ & 0.66 \\
\hline & Group & 11.53 & $(1,63)$ & 11.53 & 0.02 & 0.891 & 0.00 \\
\hline \multirow[t]{3}{*}{ PD } & Time & 1.61 & $(1,63)$ & 1.61 & 4.70 & 0.034 & 0.07 \\
\hline & Time $*$ Group & 22.66 & $(1,63)$ & 22.66 & 66.03 & $<0.001$ & 0.51 \\
\hline & Group & 19.97 & $(1,63)$ & 19.97 & 3.31 & 0.073 & 0.05 \\
\hline \multirow[t]{3}{*}{ ICI } & Time & 5.06 & $(1,63)$ & 5.06 & 14.88 & $<0.001$ & 0.19 \\
\hline & Time $*$ Group & 25.99 & $(1,63)$ & 25.99 & 76.35 & $<0.001$ & 0.55 \\
\hline & Group & 0.05 & $(1,63)$ & 0.05 & 0.01 & 0.919 & 0.00 \\
\hline \multirow[t]{3}{*}{ CREA } & Time & 36.23 & $(1,63)$ & 36.23 & 7.91 & 0.007 & 0.11 \\
\hline & Time $*$ Group & 1956.23 & $(1,63)$ & 1956.23 & 426.94 & $<0.001$ & 0.87 \\
\hline & Group & 243.15 & $(1,63)$ & 243.15 & 0.28 & 0.602 & 0.00 \\
\hline
\end{tabular}

Note. D2 CON = Concentration; D2 Atte = Attention; LM = Logical Memory; NM = Numerical Memory; ASS = Associative Memory; AIM = Total Immediate Auditory Memory; DP = Difference Perception; ICI = Impulsivity Control Index; CREA = Creativity. 
AIM: (C) Logical Memory, (D) Numerical Memory, (E) Associative Memory, and (F) total AIM

The results for the Logical Memory variables showed a main effect of Time and a double interaction Time $\times$ Group. Planned post hoc comparison showed a significant increase between Pre and Post for the EG, $\mathrm{t}(63)=-5.63, p_{\text {bonferroni }}<0.001$. For the variable Numerical Memory, the results also showed the main effect of Time and a double interaction Time $\times$ Group. Planned post hoc comparisons showed significant differences between the EG and the CG at Pre, $\mathrm{t}(63)=2.67, p_{\text {bonferroni }}=0.043$, between Pre and Post for the CG, $t(63)=-3.76, p_{\text {bonferroni }}=0.002$, between Pre and Post for the EG, $\mathrm{t}(63)=-16.65, p_{\text {bonferroni }}<0.001$, and finally between the EG and the CG for Post, $\mathrm{t}(63)=-3.11, p_{\text {bonferroni }} \mathrm{i}=0.016$.

These results indicate that even though there was an initial difference in the Pre measure between the groups, and although both groups improved significantly, the improvement was greater in the case of the EG. For associative memory, the analyses showed an effect of Time and a double interaction of Time $\times$ Group. Post hoc comparisons showed a significant difference between Pre and Post for the EG, $t(63)=12.19, p_{\text {bonferroni }}>0.001$. The results for total AIM showed an effect of Time, and a double Time $\times$ Group interaction. Post hoc comparisons showed significant differences between Pre and Post for the CG, $\mathrm{t}(63)=-3.12, p_{\text {bonferroni }}=0.017$, and for the $\mathrm{EG}, \mathrm{t}(63)=-19.19, p_{\text {bonferroni }}>0.001$.

FACE-R: (G) Difference Perception and (H) Impulsivity Control Index

The results for Difference Perception analysis showed a main effect of Time and a double interaction of Time $\times$ Group. Post hoc comparisons showed differences between Pre and Post for the CG group, $\mathrm{t}(63)=4.12, p_{\text {bonferroni }}>0.001$, and for the $\mathrm{EG}, \mathrm{t}(63)=-7.45$, $p_{\text {bonferroni }}>0.001$. In addition, the difference between Post scores between the two groups was also significant, $t(63)=-3.12, p_{\text {bonferroni }}=0.017$. The results indicate that, while the EG improved after the intervention, the CG worsened. In the case of the Impulsivity Control Index variable, analyses showed a main effect of Time and a double interaction of Time $\times$ Group. Post hoc comparison showed differences between Pre and Post for both groups, $\mathrm{t}(63)=8.71, p_{\text {bonferroni }}>0.001$ for the $C G$, and $\mathrm{t}(63)=3.53, p_{\text {bonferroni }}=0.005$ for the EG. These results indicate that both groups experienced changes in impulsivity after the intervention, although impulsivity decreased in the EG, and it increased in the CG.

(I) Creativity

Finally, findings for the Creativity variable showed a main effect of Time and a double interaction of Time $\times$ Group. Planned post hoc comparison again showed differences between Pre and Post for both groups, $\mathrm{t}(63)=12.34$, $p_{\text {bonferroni }}>0.001$ for the CG, and $\mathrm{t}(63)=17.00, p_{\text {bonferroni }}>0.001$ for the EG. Again, within-group differences after the intervention showed opposite patterns; while the EG improved, the CG worsened.

Finally, the correlations between the post-intervention scores were studied. Table 4 shows the correlation matrix of the Post scores for each of the CG and EG groups. It is noteworthy that, in the case of the EG, the Numerical Memory (NM) scores correlated significantly with Concentration and Attention ( $\mathrm{r}=0.55$ and 0.36 , respectively), but not so in the case of the CG. Patterns of differential correlation between the groups can also be observed for the variables ICI and CREA. In the case of ICI in the EG, there is a significant correlation with Concentration $(r=0.42)$ compared to the CG. However, in the CG, the ICI correlates with ASS( $r=0.46)$, which is not the case for the EG. Finally, we can highlight that the CREA variable also seems to show different correlation patterns between the groups. In the CG, it correlates with Atte, $\mathrm{NM}$, and $\mathrm{AM}(\mathrm{r}=0.55,0.53$, and 0.75 , respectively) but these variables do not correlate in the EG. However, in the EG, the CREA correlates with DP and with ICI ( $r=0.46$ and 0.57 , respectively), but not in the CG. 
Table 4. Correlation matrix of Post DV for each group.

\begin{tabular}{|c|c|c|c|c|c|c|c|c|c|c|c|c|c|c|c|c|c|c|}
\hline & DV & & Con & & Atte & & LM & & NM & & AM & & AIM & & PD & & ICI & CREA \\
\hline \multirow[t]{16}{*}{ EG } & Con & $r$ & - & & & & & & & & & & & & & & & \\
\hline & Atte & $\begin{array}{l}p \\
r\end{array}$ & 0.61 & $* * *$ & - & & & & & & & & & & & & & \\
\hline & Кне & $p$ & $<0.001$ & & 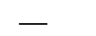 & & & & & & & & & & & & & \\
\hline & LM & $r$ & 0.85 & $* * *$ & 0.57 & $* * *$ & - & & & & & & & & & & & \\
\hline & & $p$ & $<0.001$ & & $<0.001$ & & $=$ & & & & & & & & & & & \\
\hline & NM & $r$ & 0.55 & $* * *$ & 0.36 & * & 0.56 & $* * *$ & - & & & & & & & & & \\
\hline & & $p$ & $<0.001$ & & 0.037 & & $<0.001$ & & - & & & & & & & & & \\
\hline & $\mathrm{AM}$ & $r$ & 0.67 & $* * *$ & 0.52 & $* *$ & 0.80 & $* * *$ & 0.56 & $* * *$ & - & & & & & & & \\
\hline & & $p$ & $<0.001$ & & 0.002 & $\forall * *$ & $<0.001$ & 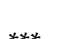 & $<0.001$ & & - & & & & & & & \\
\hline & AIM & $r$ & 0.81 & $* * *$ & 0.57 & $* * *$ & 0.94 & $* * *$ & 0.72 & $* * *$ & 0.92 & **** & - & & & & & \\
\hline & DP & $\begin{array}{l}p \\
r\end{array}$ & $\begin{array}{l}<0.001 \\
0.44\end{array}$ & $*$ & $\begin{array}{l}<0.001 \\
0.50\end{array}$ & $* *$ & $\begin{array}{l}<0.001 \\
0.61\end{array}$ & $* * *$ & $\begin{array}{l}<0.001 \\
0.39\end{array}$ & $*$ & $\begin{array}{l}<0.001 \\
0.63\end{array}$ & $* * *$ & $\overline{0.65}$ & $* * *$ & - & & & \\
\hline & & $p$ & 0.010 & & 0.002 & & $<0.001$ & & 0.021 & & $<0.001$ & & $<0.001$ & & - & & & \\
\hline & ICI & $r$ & 0.42 & $*$ & 0.18 & & 0.46 & $* *$ & 0.25 & & 0.31 & & 0.41 & * & 0.59 & $* * *$ & - & \\
\hline & & $p$ & 0.012 & & 0.297 & & 0.006 & & 0.148 & & 0.074 & & 0.016 & & $<0.001$ & & - & \\
\hline & CREA & $r$ & 0.42 & $*$ & 0.08 & & 0.42 & * & 0.27 & & 0.34 & & 0.40 & * & 0.46 & $* *$ & 0.57 & - \\
\hline & & $p$ & 0.014 & & 0.665 & & 0.014 & & 0.117 & & 0.052 & & 0.018 & & 0.006 & & $<0.001$ & - \\
\hline \multirow[t]{16}{*}{ CG } & Con & $r$ & - & & & & & & & & & & & & & & & \\
\hline & Atte & $\begin{array}{l}p \\
r\end{array}$ & $\overline{0.71}$ & $* * *$ & - & & & & & & & & & & & & & \\
\hline & & $p$ & $<0.001$ & & - & & & & & & & & & & & & & \\
\hline & LM & $r$ & 0.74 & $* * *$ & 0.61 & $* * *$ & - & & & & & & & & & & & \\
\hline & NIM & $p$ & $<0.001$ & & $<0.001$ & & $\overline{0}=0$ & & & & & & & & & & & \\
\hline & NM & $r$ & 0.26 & & 0.26 & & 0.39 & * & - & & & & & & & & & \\
\hline & $\mathrm{AM}$ & $\begin{array}{l}p \\
r\end{array}$ & $\begin{array}{l}0.160 \\
0.51\end{array}$ & $* *$ & $\begin{array}{l}0.159 \\
0.44\end{array}$ & * & $\begin{array}{l}0.031 \\
0.75\end{array}$ & $* * *$ & $\overline{0.55}$ & ** & - & & & & & & & \\
\hline & & $p$ & 0.003 & & 0.014 & & $<0.001$ & & 0.001 & & - & & & & & & & \\
\hline & AIM & $r$ & 0.65 & $* * *$ & 0.55 & $* *$ & 0.91 & $* * *$ & 0.65 & $* * *$ & 0.92 & $* * *$ & - & & & & & \\
\hline & & $p$ & $<0.001$ & & 0.001 & & $<0.001$ & & $<0.001$ & & $<0.001$ & & - & & & & & \\
\hline & DP & $r$ & 0.49 & $* *$ & 0.39 & * & 0.43 & * & 0.04 & & 0.49 & $* *$ & 0.43 & * & - & & & \\
\hline & & $p$ & 0.005 & & 0.028 & & 0.015 & & 0.842 & & 0.006 & & 0.015 & & - & & & \\
\hline & ICI & $r$ & 0.30 & & 0.19 & & 0.40 & * & 0.27 & & 0.46 & $* *$ & 0.46 & $* *$ & 0.75 & $* * *$ & - & \\
\hline & & $p$ & 0.100 & & 0.311 & & 0.026 & & 0.142 & & 0.008 & & 0.009 & & $<0.001$ & & - & \\
\hline & CREA & $r$ & 0.68 & $* * *$ & 0.55 & $* *$ & 0.84 & $* * *$ & 0.53 & $* *$ & 0.75 & $* * *$ & 0.87 & $* * *$ & 0.31 & & 0.27 & - \\
\hline & & $p$ & $<0.001$ & & 0.001 & & $<0.001$ & & 0.002 & & $<0.001$ & & $<0.001$ & & 0.093 & & 0.144 & - \\
\hline
\end{tabular}

Note. Con = Concentration; Atte = Attention; LM = Logical Memory; NM = Numerical Memory; AM = Associative Memory; AIM = Total Immediate Auditory Memory; DP = Difference Perception; ICI = Impulsivity Control Index; CREA = Creativity; $\mathrm{r}=$ Pearson $\mathrm{r} ;{ }^{*} p<0.05$, ${ }^{* *} p<0.01,{ }^{* * *} p<0.001$

\section{Discussion}

The aim of our study was to analyze the effects of an 8-week intervention using the soroban abacus on memory, concentration, attention, perceptive attitudes, and creativity in children aged 7-11.

The key findings of this study show that both concentration and memory are significantly improved after the intervention with mental calculation exercises. These results have important implications on the child's school development, since these parameters are strongly associated with the child's academic performance and his or her level of success when learning in all fields, but especially in the mathematical area because of the skill that is achieved thanks to this Japanese technique. Furthermore, we observed that creativity improved among children, due to the development of these skills, helps, above all, to improve their self-expression, their abstract thinking, their capacity to solve problems, and mainly, to favor socialization [43].

Currently, there are few randomized clinical trials focusing on the effects that the use of the abacus may have on these psychological factors.

Our study reported that memory was significantly better in abacus-trained children compared to the control group. Similarly, in the scientific literature, we can find other studies that carried out the same intervention and found significant improvements in this cognitive parameter, but unlike our study, the intervention time was much longer, as, for example, in the study by Irwing et al. [44], which carried out a 34-week intervention, or in the study by Bhaskaran et al. [16], which reported significant improvements over a one-year cross-sectional study with the abacus.

Clearly, only people with abacus training can interpret what they are attending to decode the number represented by an abacus. This can explain the significant results in 
improving scores for perceptive attitudes, as this skill allows one to quickly and accurately identify the result of a combination of cards in the abacus. Studies like the one by Du et al. [45] also studied the use of the abacus for the improvement of this parameter with their participants and found significant differences. However, in their study, the children already had previous experience with the abacus, so it cannot be extrapolated with our results since our participants had not had contact with this instrument nor had they received any notions about its use.

Concentration is one of the key factors that children must have in order to achieve full cognitive potential. In the present study, participants who received training based on the use of the abacus showed improvements in concentration after 8 weeks. Similarly, there are studies that report improvements in concentration, but with other types of cognitive training, such as the study with primary school students demonstrating an improvement in the ability to concentrate, as measured by the D2 test, after music training based on listening, imitation, and memorization for 18 months [46]. On the other hand, the efficiency of physical exercise on concentration capacity and academic performance has also been demonstrated [47]. Therefore, new studies should be considered to evaluate the benefits of a combined physical-cognitive program in order to assess what the improvements are and, thus, be able to compare them with previous studies and see the results obtained in this cognitive parameter [48].

In the study of selective attention, no significant improvements were found with respect to the control group. In investigating the scientific literature, we have been able to find a study [49] that found improvements for this variable, but in children who are above the seventh level of abacus use, according to the International Association of Abacus and Arithmetic; on the other hand, in our study, one of the criteria of inclusion was that the children could not have had experience in the use of the abacus.

Our results found that the scores for the creativity component improved after the abacus intervention. These results are contrasted with a recent systematic review by Wang [1], which suggests that AMC training has the potential to improve several cognitive skills, including mathematics, working memory, and numerical magnitude processing [39]. AMC involves multiple cognitive processes, such as transforming digital stimuli into mental images, keeping multiple components of the imaginary abacus in working memory, and blocking environmental interference. It may be due to this that an improvement of this cognitive variable is significant, although more studies using the abacus would be needed to verify that the improvement starts from this premise.

This research is not free of limitations, which have to be considered. Firstly, the timing of the intervention is a factor. The intervention lasted 8 weeks, so we could not analyze the learning gains achieved long-term. The number of participants is another limitation. Further studies with larger samples would be desirable to see if these findings are replicable. The context in which it was conducted is another factor that should be considered when analyzing these results. Unlike other research conducted in formal institutions, such as schools, this research was carried out in an educational support institution, where the student ratio is smaller and, therefore, there is more personalized attention paid to the students. Moreover, our control group was not an active control group. In this regard, further research could try to consider an active control group where an alternative action to the traditional one would be considered.

According to our results, we would recommend the training of the abacus to improve the attention of children between 7 and 11 years old. In addition, future comparative studies with large samples and prospective designs should be conducted to more accurately assess the possible role of abacus training in neurocognitive functioning among children.

\section{Conclusions}

The present study carried out in children aged between 7 and 11 years, had two main research questions. Firstly, it was intended to find out whether there was a relationship between AMC training and cognitive skills. Regarding the relationship, it was found 
that the experimental group participants improved their concentration cognitive abilities, immediate auditory memory, perceptive attitudes, and creativity. In terms of assessing whether AMC training improves students' mathematical skills, the findings suggest the effectiveness of the use of the abacus in learning calculation, due to the higher EG scores compared to the CG's in just 8 weeks. These results are an advance for both the field of education and clinical practice since they reinforce the important role of the abacus for working in the classroom, and outside it, in order to achieve benefits at the psychological level that are useful for better academic achievements.

Author Contributions: Conceptualization, M.d.C.C.F.; methodology, M.d.C.C.F. and S.P.L.; software, S.P.L.; formal analysis, S.P.L.; investigation, I.G.-M.; writing-original draft preparation, M.d.C.C.F., S.P.L. and I.G.-M.; writing-review and editing, M.d.C.C.F., S.P.L. and I.G.-M.; supervision, S.P.L. and I.G.-M. All authors have read and agreed to the published version of the manuscript.

Funding: This research received no external funding.

Institutional Review Board Statement: Ethical review and approval were waived for this study, due to one of the researchers (M.d.C.C.F.) works for the company Aloha mental Arithmetic and the research is supported by this company, which is guaranteed by the Spanish Society of Pedagogy.

Informed Consent Statement: Informed consent was obtained from all subjects involved in the study.

Data Availability Statement: The data presented in this study are available on request from the corresponding author.

Conflicts of Interest: The authors declare no conflict of interest.

\section{References}

1. Wang, C. A review of the effects of abacus training on cognitive functions and neural systems in humans. Front. Neurosci. 2020. [CrossRef] [PubMed]

2. Sohn, W.S.; Lee, T.Y.; Kwak, S.; Yoon, Y.B.; Kwon, J.S. Higher extrinsic and lower intrinsic connectivity in resting state networks for professional Baduk (Go) players. Brain Behav. 2017, 7, e00853. [CrossRef]

3. Belkacem, A.N.; Kiso, K.; Uokawa, E.; Goto, T.; Yorifuji, S.; Hirata, M. Neural processing mechanism of mental calculation based on cerebral oscillatory changes: A comparison between abacus experts and novices. Front. Hum. Neurosci. $2020,14,137$. [CrossRef]

4. Zhou, H.; Geng, F.; Wang, Y.; Wang, C.; Hu, Y.; Chen, F. Transfer effects of abacus training on transient and sustained brain activation in the frontal-parietal network. Neuroscience 2019, 408, 135-146. [CrossRef]

5. Hu, Y.; Geng, F.; Tao, L.; Hu, N.; Du, F.; Fu, K.; Chen, F. Enhanced white matter tracts integrity in children with abacus training. Hum. Brain Mapp. 2011, 32, 10-21. [CrossRef] [PubMed]

6. Li, Y.; Chen, F.; Huang, W. Neural plasticity following abacus training in humans: A review and future directions. Neu Plastic. 2016. [CrossRef] [PubMed]

7. Wang, C.; Weng, J.; Yao, Y.; Dong, S.; Liu, Y.; Chen, F. Effect of abacus training on executive function development and underlying neural correlates in Chinese children. Hum. Brain Mapp. 2017, 38, 5234-5249. [CrossRef]

8. Dong, S.; Wang, C.; Xie, Y.; Hu, Y.; Weng, J.; Chen, F. The impact of abacus training on working memory and underlying neural correlates in young adults. Neuroscience 2016, 332, 181-190. [CrossRef] [PubMed]

9. Jones, D.K.; Knosche, T.R.; Turner, R. White matter integrity, fiber count, and other fallacies: The do's and don'ts of diffusion MRI. Neuroimage 2013, 73, 239-254. [CrossRef] [PubMed]

10. Huang, J.; Du, F.L.; Yao, Y.; Wan, Q.; Wang, X.S.; Chen, F.Y. Numerical magnitude processing in abacus-trained children with superior mathematical ability: An EEG study. J. Zhejiang Univ. Sci. B 2015, 16, 661-671. [CrossRef] [PubMed]

11. Amo, D.; Fox, P.; Fonseca, D.; Poyatos, C. Systematic Review on Which Analytics and Learning Methodologies Are Applied in Primary and Secondary Education in the Learning of Robotics Sensors. Sensors 2021, 21, 153. [CrossRef]

12. Li, Y.; Hu, Y.; Zhao, M.; Wang, Y.; Huang, J.; Chen, F. The neural pathway underlying a numerical working memory task in abacus-trained children and associated functional connectivity in the resting brain. Brain Res. 2013, 1539, 24-33. [CrossRef]

13. Weng, J.; Xie, Y.; Wang, C.; Chen, F. The Effects of Long-term Abacus Training on Topological Properties of Brain Functional Networks. Sci. Rep. 2017, 7, 8862. [CrossRef]

14. Wang, C.; Geng, F.; Yao, Y.; Weng, J.; Hu, Y.; Chen, F. Abacus Training Affects Math and Task Switching Abilities and Modulates Their Relationships in Chinese Children. PLoS ONE 2015, 10, e0139930. [CrossRef] [PubMed]

15. Philip, S.; Wing Chee, S. A Feel for Numbers: The Changing Role of Gesture in Manipulating the Mental Representation of an Abacus Among Children at Different Skill Levels. Front. Psychol. 2018, 9, 1267. [CrossRef]

16. Bhaskaran, M.; Sengottaiyan, A.; Madhu, S.; Ranganathan, V. Evaluation of memory in abacus learners. Indian J. Physiol. Pharm. 2006, 50, 225-233. 
17. Lustig, C.; Shah, P.; Seidler, R.; Reuter-Lorenz, P.A. Aging, training, and the brain: A review and future directions. Neuropsychol. Rev. 2009, 19, 504-522. [CrossRef] [PubMed]

18. Zhou, H.; Geng, F.; Wang, T.; Wang, C.; Xie, Y.; Hu, Y.; Chen, F. Training on Abacus-based Mental Calculation Enhances Resting State Functional Connectivity of Bilateral Superior Parietal Lobules. Neuroscience 2020, 432, 115-125. [CrossRef]

19. Frank, C.; Barner, D. Representing exact number visually using mental abacus. J. Exp. Psychol. Gen. 2012, 141, 134-149. [CrossRef] [PubMed]

20. Wang, Y.; Geng, F.; Hu, Y.; Du, F.; Chen, F. Numerical processing efficiency improved in experienced mental abacus children. Cognition 2013, 127, 149-158. [CrossRef] [PubMed]

21. Zatorre, R.J.; Fields, R.D.; Johansen-Berg, H. Plasticity in gray and white: Neuroimaging changes in brain structure during learning. Nat. Neurosci. 2012, 15, 528-536. [CrossRef] [PubMed]

22. Josipovic, Z.; Dinstein, I.; Weber, J.; Heeger, D.J. Influence of meditation on anti-correlated networks in the brain. Front. Hum. Neurosci. 2011, 5, 183. [CrossRef] [PubMed]

23. López Guerrero, C. Cerebral hemisphere stimulation program in learning cosntruction of 5 year old children in initial Education of Yungar District in Carhuaz. Bing Bang Faustiniano 2019, 8, 44-48.

24. Donlan, C.; Wu, C. Procedural complexity underlies the efficiency advantage in abacus-based arithmetic development. Cogn. Dev. 2017, 43, 14-24. [CrossRef]

25. Kelly, C.; Castellanos, F.X. Strengthening connections: Functional connectivity and brain plasticity. Neuropsychol. Rev. 2014, 24, 63-76. [CrossRef]

26. Fernández, I. Competencia en cálculo mental con el Ábaco Japonés. Números. Rev. Didác. Matem. 2018, 99, 141-152.

27. Tanaka, S.; Seki, K.; Hanakawa, T.; Harada, M.; Sugawara, S.K.; Sadato, N.; Watanabe, K.; Honda, M. Abacus in the brain: A longitudinal functional MRI study of a skilled abacus user with a right hemispheric lesion. Front. Psychol. 2012, 3, 315. [CrossRef]

28. Meke, K.D.P.; Wutsqa, D.U.; Alfi, H.D. The Effectiveness of Problem-based Learning Using Manipulative Materials Approach on Cognitive Ability in Mathematics Learning. J. Phys. Conf. Ser. 2018, 1097. [CrossRef]

29. Ku, Y.; Hong, B.; Zhou, W.; Bodner, M.; Zhou, Y.D. Sequential neural processes in abacus mental addition: An EEG and fMRI case study. PLOS ONE 2012, 7, e36410. [CrossRef] [PubMed]

30. Wu, H.; Li, L. Development of Chinese rating scale of pupil's mathematic abilities and study on its reliability and validity. China Public Health. 2005, 21, 473-475.

31. Cui, J.; Xiao, R.; Ma, M.; Yuan, L.; Cohen Kodash, R.; Zhou, X. Children skilled in mental abacus show enhanced non-symbolic number sense. Curr. Psychol. 2020, 1-14. [CrossRef]

32. Kalbkhani, E.; Sameri, M. Effectiveness of Mental Calculation Training by Abacus on reducing the learning disability of math in third grade elementary school students. Empower. Except. Child. 2020, 11, 101-116. [CrossRef]

33. Seisdedos, N. Adapt. Española D2, Test de Atención de Brickenkamp; TEA Ediciones: Madrid, Spain, 2012.

34. Pawlowski, J. Test de Atención d2: Consistencia interna, estabilidad temporal y evidencias de validez/The d2 Test of Attention: Internal Consistency, Temporal Stability and Evidence of Validity. Rev. Costar. Psico. 2020, 39, 145-165.

35. Thurstone, L.L.; Yela, M. CARAS-R. Test de Percepción de Diferencias-Revisado; Tea Ediciones: Madrid, Spain, 2012.

36. Ison, M.S.; Carrada, M. Tipificación argentina del Test de Percepción de Diferencias (CARAS). In Test de Percepción de Diferencias Revisado (CARAS-R); Louis Leon, T., Mariano, Y., Eds.; Tea Edition: Madrid, Spain, 2012; pp. 37-63.

37. Cordero, P.A. Adaptación para Lima Metropolitana de Dioses, A. Test de Memoria Auditiva Inmediata, 7th ed.; TEA Ediciones: Madrid, Spain, 2009.

38. Dioses, A.; Manrique, S.; Segura, K. Adaptación del Test de Memoria Inmediata (MAI); Centro de Investigación y Publicaciones CPAL: Lima, Peru, 2002.

39. Corbalán, F.J. Crea, Inteligencia Creativa: Una Medida Cognitiva de la Creatividad; TEA Ediciones: Madrid, Spain, 2006.

40. López Martínez, O.; Navarro, J. Creatividad e inteligencia: Un estudio en Educación Primaria. Rev. Investig. Educat. 2008, 28, 283-296.

41. World Medical Association. Declaration of Helsinki. Ethical principles for medical research involving human subjects. Jahrbuch für Wissenschaft Und Ethik 2009, 14, 233-238.

42. The Jamovi Project. Jamovi (Version 1.2) [Computer Software]. 2020. Available online: https://www.jamovi.org (accessed on 11 June 2020).

43. Pérez-Fernández, J.I.; Garaigordobil-Landazabal, M.; Adrada, Z.; de Miguel, L. Effects of an education program for coexistence on creative and socio-emotional development factors for children aged 7-11 years. Summa Psicológica UST 2011, 8, 5-17. [CrossRef]

44. Irwing, P.; Hamza, A.; Khaleefa, O.; Lynn, R. Effects of Abacus training in the intelligence on Sudanese children. Pers. Individ. Differ. 2008, 45, 694-696. [CrossRef]

45. Du, F.; Yao, Y.; Zhang, Q.; Chen, F. Long-term abacus training induces automatic processing of abacus numbers in children. Perception 2014, 43, 694-704. [CrossRef] [PubMed]

46. Barbaroux, M.; Dittinger, E.; Besson, M. Music training with Demos program positively influences cognitive functions in children from low socio-economic backgrounds. PLoS ONE 2019, 14, e0216874. [CrossRef]

47. Rasmussen, M.; Laumann, K. The academic and psychological benefits of exercise in healthy children and adolescents. Eur. J. Psych. Educ. 2013, 28, 945-962. [CrossRef] 
48. Na, K.S.; Lee, S.; Park, J.H.; Jung, H.Y.; Ryu, J.H. Association between Abacus Training and Improvement in Response Inhibition: A Case-control Study. Clin. Psychophar. Neurosc. 2015, 13, 163-167. [CrossRef] [PubMed]

49. Sala, G.; Burgoyne, A.P.; Macnamara, B.N.; Hambrick, D.Z.; Campitelli, G.; Gobet, F. Checking the "Academic Selection" argument. Chess players outperform non-chess players in cognitive skills related to intelligence: A meta-analysis. Intelligence 2017, 61, 130-139. [CrossRef] 